\title{
Racismo e sua negação 0 caso dos imigrantes bolivianos em São Paulo
}

\author{
Szilvia Simai * \\ Rosana Baeninger **
}

Com uma trajetória de quase meio século no Brasil, iniciada com as migrações de fronteira (PERES, 2009), a imigração boliviana em São Paulo representa, na atualidade, o fluxo migratório internacional de maior visibilidade e estudos para a cidade (SILVA, 2006). Assim, o enfoque inovador deste artigo é baseado em estudo discursivo de brasileiros acerca dos imigrantes bolivianos que vivem em São Paulo, bem como das análises de discursos presentes no interior do próprio grupo imigrante ${ }^{1}$.

O termo "discurso" refere-se a uma forma de prática social que se manifesta na conversa e comunicação, juntamente com outras expressões não verbais. Este trabalho tem por objetivo oferecer uma exploração de vários exemplos discursivos da negação da existência de racismo, xenofobia e conflitos em ambos os lados. $O$ estudo indica o proeminente papel que a negação desempenha no discurso contemporâneo em relação às questões raciais e étnicas entre os imigrantes bolivianos e brasileiros na cidade de São Paulo.

Pesquisas têm demonstrado que a negação de racismo por grupos étnicos majoritários (PETROVA, 2000; VAN DIJK, 2002) e pela sociedade hospedeira (PETROVA, 2000; BILLIG, 1997), também no contexto migratório, tem se tornado a forma discursiva característica do racismo moderno. A negação, como forma

\footnotetext{
* Doutora em Psicologia Social; Núcleo de Estudos de População/Universidade Estadual de Campinas.

** Doutora em Ciências Sociais; Departamento de Demografia e Núcleo de Estudos de População/ Universidade Estadual de Campinas.
} 
retórica, tornou-se uma resposta difundida para minorias e também migrantes, apesar de apresentar diferentes motivos psicossociais. Neste trabalho, o termo racismo refere-se ao sistema de racismo, consistindo em um subsistema social e cognitivo (VAN DIJK, 2002); assim, inclui - sem se limitar a - atitudes, opções, afirmações, políticas e ações.

A metodologia utilizada para este artigo baseou-se em grupos focais objetivando apreender a negação do racismo como retórica social contemporânea. Tais grupos foram conduzidos entre 26 e 28 de fevereiro de 2011, com 24 estudantes de graduação dos cursos de Psicologia, Comunicação e Economia da Universidade de São Paulo. Todos os participantes nasceram na cidade de São Paulo, encontravam-se na faixa etária dos 18 a 50 anos de idade, tendo como declaração de raça/cor 5 amarelos, 8 negros e 12 brancos.

Para entendermos a prática discursiva presente na imigração boliviana, foram realizadas 15 entrevistas individuais em profundidade, das quais $13 \mathrm{com}$ mulheres imigrantes bolivianas e 2 entrevistas com imigrantes bolivianos, com idade entre 21 e 53 anos. As ocupações principais dessas imigrantes mulheres eram: costureira, enfermeira, empregada doméstica e advogada; entre os homens bolivianos, um era costureiro e o outro publicitário. As entrevistas foram gravadas e transcritas para posterior análise de discurso individual. Essas entrevistas permitiram explorar os projetos migratórios e analisar a experiência subjetiva através de cada narrativa individual.

Em termos de análise, as declarações dos participantes não são representativas da personalidade dos indivíduos, de atitudes pessoais ou de processos cognitivos subjacentes (EDWARDS \& POTTER,1992, 1993; POTTER \& WETHERELL, 1987, 1995); trata-se de articulações de narrativas correntes, socialmente disponíveis nas relações intragrupo e intergrupo de brasileiros e bolivianos na cidade de São Paulo. Tanto nos grupos focais, quanto nas entrevistas em profundidade, a ênfase esteve ancorada na análise de como 'o outro' é interpretado, quer seja brasileiro, quer seja imigrante boliviano; atentou-se também para os recursos discursivos empregados e suas finalidades.

Interpretações discursivas informam e regulam o comportamento (PARKER and BURMAN, 1993); ou seja, demonstram como as pessoas posicionam a si mesmas e como se posicionam em relação aos outros. Entretanto, apesar de os sujeitos poderem ser agentes na escolha de suas interpretações da realidade social, tais discursos são construídos por contextos histórico-sociais. Nesse sentido, o discurso em ação, as verbalizações dos sujeitos, refletem ideologias que se tornaram experiências vividas.

Assim, o artigo busca conhecer as características específicas dos construtos discursivos de bolivianos e brasileiros, em suas interações sociais na cidade de São Paulo, a fim de avançar no entendimento das atitudes e práticas sociais dos grupos envolvidos. 


\section{Formas discursivas contemporâneas de negação do racismo}

A negação é uma forma discursiva de expressão e repressão do que é proibido socialmente (FREUD, 1950). Consiste em uma forma de discurso usada, habitualmente, na comunicação diária (BILLIG, 1997), tornando-se a maneira mais marcante, na contemporaneidade, para lidar com atitudes, afirmações, pontos de vista, ações e políticas que são condenadas moral e ideologicamente (BILLIG, 1997).

É nesse contexto que emergem negações do racismo e da xenofobia, embora tais fenômenos estejam submersos nas sociedades (ARENDT, 1970). De fato, após a Segunda Guerra Mundial, o racismo e a xenofobia foram ideologias moralmente condenadas e proibidas, reprimidas e negadas discursivamente (PETROVA, 2000). Consequentemente, a negação do racismo como forma discursiva em práticas sociais é, ironicamente, "fruto do progresso da luta contra ela mesma" (PETROVA, 2000, p. 28).

A partir das entrevistas realizadas com brasileiros e com imigrantes bolivianos, foi possível identificar as formas de negação do racismo existente, atualmente, no convívio social paulistano.

\section{Brasileiros falando sobre bolivianos}

A narrativa dos jovens universitários brasileiros, a partir dos grupos focais, possibilitou identificar um discurso bastante marcado pela imagem do Brasil como um país receptivo à imigração; os brasileiros foram descritos como muito receptivos e respeitosos aos vários grupos étnicos e raciais provenientes de qualquer lugar do mundo. Enfatizaram, contudo, que isto não se verifica para os brasileiros que estão no exterior.

Dois outros pontos foram também importantes: a preocupação com as diferenças entre o nós positivo (brasileiros) e os negativos ou exóticos "outros", e as questões sobre discriminação racial ou étnica.

Várias escolhas discursivas de negação permearam as discussões, inclusive negações de racismo com base em empatia, ignorância aparente, transferência e negação explícita (PETROVA, 2000; SIMAI \& BAENINGER, 2011). Os tópicos abaixo identificam as formas retóricas de negação racista encontradas nos discursos dos brasileiros acerca dos bolivianos residentes em São Paulo.

\section{a) Representações sociais positivas e negativas da imigração boliviana}

Estudos internacionais sobre conversas a respeito de imigrantes apontam a imagem negativa que a sociedade receptora tem sobre os mesmos. De acordo com Teun Van $(1984,1987)$, quando se trata de imigrantes, os aspectos da discussão são predominantemente negativos; ao serem casualmente perguntados sobre suas vizinhanças, os entrevistados tendem, espontaneamente, a falar de forma negativa sobre os estrangeiros (VAN DIJK, 2002; WETHERELL \& POTTER, 1992). 
No caso dos bolivianos em São Paulo, ficou evidente também a predominância de aspectos negativos acerca desses imigrantes e suas condições de vida. Através dos trechos abaixo indicados, é possível verificar a ênfase negativa sobre o imigrante boliviano. A pobreza, o sofrimento e a semiescravidão expressam o imaginário social dos brasileiros frente ao grupo imigrante (trechos 1, 2 e 4). No trecho 5, delimitam o "outro negativo" e o "nós positivo", através da concepção de estrangeiros moralmente não aceitáveis, violentos e agressivos, diferentes dos brasileiros.

Moderador: O tema, hoje, é sobre os imigrantes bolivianos em São Paulo. Como você se sente diante deste assunto?

1. [...] Sei que eles têm muitas dificuldades aqui em São Paulo, que são semiescravos no trabalho.

2. [...] Quando visitei a Bolívia, tive a impressão de que o país era muito pobre. Mas eles também não são refugiados aqui.

3. Quando você mencionou o assunto, a primeira coisa que veio à minha mente foi uma feira semanal de artesãos aqui em São Paulo. Moderador: Você esteve lá?

4. Não, nunca, mas sei que existe. Isso me fez pensar sobre a riqueza cultural que eles trazem para cá, mas ao mesmo tempo sei que essa feira é resultado de muitos bolivianos que vêm aqui e se envolvem em trabalhos muito difíceis, como ela disse, sofrendo muito. Eles trabalham e moram no mesmo lugar.

5. Ouvi dizer que na favela aqui perto há um grande contingente de bolivianos. Portanto... eles são diferentes de nós. Por exemplo, para eles é normal bater em mulher [...]. Eles têm dificuldade em muitos trabalhos que fazem... eles vêm aqui em busca de trabalho...

6. A primeira coisa que pensei, quando começamos a falar, foi nos produtos

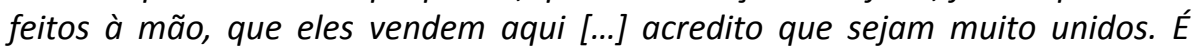
isso que eu vejo, eles parecem uma espécie de tribo, a família toda caminha junto, possuem olhos mais orientais, vestem roupas coloridas e vendem seus artesanatos.

7. [...] a cultura deles é muito antiga e tem-se a impressão de que as pessoas carregam essa coisa antiga, indígena, em suas vidas e cultura [...] então, eles são muito ricos culturalmente.

A construção social negativa é, contudo, contrabalançada pela exaltação cultural (representação positiva) daqueles imigrantes, como forma retórica da negação do racismo. Os brasileiros consideraram os bolivianos como "outro": exóticos, culturalmente ricos, mas economicamente pobres, conforme resumido nos trechos 3,4 e 7 . De fato, na análise de discurso sobre negações de racismo, os aspectos positivos ocorrem para enfatizar as diferenças com relação ao "outro"; considerar os estrangeiros exóticos ou provedores de enriquecimento cultural reflete o olhar para o "diferente". No caso dos 
grupos focais, a conclusão para esse tópico foi sintetizada através da seguinte verbalização: "Nós, brasileiros, vemos a Bolívia como uma nação de povo pobre, mas de passado culturalmente rico".

\section{b) Brasil, terra de imigrantes: autorrepresentação positiva}

Segundo Billig (1997) e Van Dijk (2002), a negação do racismo na imigração passa também pela construção social de um país receptor e tolerante em relação aos diferentes grupos de imigrantes. De acordo com os autores, a autorrepresentação positiva é um elemento importante no discurso diário e deve ser entendida como negação argumentativa de acusações de antirracismo.

Os trechos, a seguir, ilustram as representações positivas da história da imigração para São Paulo; a diversidade de nacionalidades dentre a população da cidade (trechos 8 e 9) e, em geral, a imagem construída dos brasileiros como povo mais permissivo e receptivo (trecho 10) conduzem ao "favoritismo intragrupo" (JOST \& BURGESS, 2000).

8. Acredito que o Brasil seja um país que sempre aceitou diferenças culturais e que não deveria haver motivos para os brasileiros excluírem os outros. Os imigrantes podem manter suas culturas e mesmo assim se integrar em nossa sociedade. Temos, por exemplo, o bairro japonês em São Paulo, onde é claro que eles mantêm suas tradições japonesas e, ao mesmo tempo, participam da sociedade brasileira mais ampla.

9. Como muitos povos estrangeiros participaram do desenvolvimento do nosso país, acho que nosso povo aqui em São Paulo tem mais facilidade de viver em conjunto com outras raças e grupos étnicos. Como somos diversificados, aceitamos mais facilmente a diversidade.

10. A experiência que tenho em viajar pelos países vizinhos da América do Sul e do Norte é que os brasileiros são muito mais receptivos a estrangeiros que os outros países. Não digo que a situação aqui seja perfeita, mas os brasileiros são mais permissivos e receptivos.

A autorrepresentação positiva é fundamental para a negação do lado ruim do "nós" e do lado bom do "outro"; mostra a tendência de depreciar o outro e elogiar e glorificar a própria história, experiência e passado. Como Van Dijk analisa: "Estruturas diferentes em vários níveis [...] contribuem para a estratégia global de autoestima positiva e representação do outro, como negativa. (...) tais estruturas podem surgir e ser dirigidas à construção de estruturas mentais similares, ou seja, atitudes e ideologias negativas sobre minorias e imigração" (2002, p.158).

\section{c) O imigrante brasileiro lá fora}

Projetar-se no lugar do imigrante é um movimento retórico estratégico de negação do racismo na imigração, denominado de contra-ataque (VAN 
DIJK, 2002); o sujeito é invertido em narrativas semelhantes a esta: Não é que estejamos excluindo ou sendo racistas, nós também somos vítimas. Sofremos de racismo e exclusão em todo lugar.

Nos grupos focais, isso apareceu em forma de reclamações sobre como os brasileiros são vistos no exterior (trecho 11):

11. Acredito que se trate de outro problema, que é o da legalização. Se, por exemplo, uma brasileira vai ao exterior e tem a possibilidade de trabalhar como manicure, garçonete ou babá, ela é vista pelos outros como sendo de um país de trabalhadores de serviços. Se ela consegue ter também empregos normais, é diferente. Se todo mundo que vai para o exterior se torna manicure, então os brasileiros são vistos como um país de manicures.

Para que esse tipo de negação ocorra, torna-se necessário identificar um inimigo simbólico e dizer que o fato de sermos ou não intolerantes não é realmente a questão principal. $O$ verdadeiro problema se centra no fato de os "outros" serem intolerantes conosco.

\section{d) Estigma socioeconômico dos imigrantes}

Esta é uma forma muito comum de negação e basicamente considera a desvantagem econômica de um grupo minoritário, usando-a para negar o lado racista submerso na sociedade. Sem dúvida, em muitos casos, o grupo minoritário realmente tem pouca inserção econômica e social; mesmo assim, há um aspecto racial que está sendo negado. Petrova (2000), em uma abordagem marxista, analisou esse tipo de negação, concluindo que em tal retórica escondese o enfrentamento das questões de raça, nacionalidade e etnia.

Nas narrativas abaixo, advindas dos grupos focais, essa estratégia de mudança de questões de raça/etnia/nacionalidade para situação econômica (trecho 12) funcionou de várias maneiras. De um lado, a ênfase recaiu sobre o fato de os brasileiros estarem sofrendo, igualmente, de tal discriminação socioeconômica no país, e, portanto, isso nada tem a ver com raça/nacionalidade (trechos 13, 14 e 15). De outro lado, a questão da raça emergiu, mas vinculada ao fato de que a questão desaparece se o nível socioeconômico for elevado (trecho 16).

12. Moderador: Estamos em uma entrevista de emprego e muitos candidatos brasileirosestão presentes quando um bolivianosurge de repente. Oqueacontecerá? Entrevistado: Eu acho que ele será estigmatizado, tenho essa impressão, porque ele vem de uma região muito pobre. Exatamente como os brasileiros do Nordeste, os nordestinos são estigmatizados em São Paulo também.

13. Sim, acredito que sejam estigmatizados devido ao fato de serem pobres.

14. Não conheço muito sobre política pública, mas acho que isso tem a ver com o fato de haver muitos pobres aqui no Brasil também. Trabalhar é duro para todos nós, para os brasileiros também.

15. Acho que esse é um problema geral e não específico dos bolivianos.

16. Aqui, aqueles que têm dinheiro, como jogadores de futebol da raça negra, não são negros para a sociedade, porque possuem dinheiro. 


\section{e) O problema imigratório é mais importante lá fora: mitigação}

Análises conceituais de negação mostraram que esta pode estar também implícita em várias formas de mitigação, tais como o uso de eufemismos ou, geralmente, minimizando o ato ou a responsabilidade sobre o fenômeno (VAN DIJK, 2002).

Como mostra a narrativa 17 , a mitigação não somente ocorre no uso de eufemismo, mas pode também aparecer na retórica da atribuição de responsabilidade, e, consequentemente, na negação da culpa. A lógica psicossocial de um discurso dessa natureza reside no fato de não sermos nós os principais responsáveis pelas tensões e conflitos sociais que envolvem os imigrantes, uma vez que o problema reside em outro lugar. A responsabilidade é de outras pessoas. Aparentemente, nessa forma de negação, a própria agência está sendo disputada.

17. Tenho a impressão de que esse é um problema mais importante em outros locais, como, por exemplo, na Europa. Podemos ver na TV como é difíil imigrantes islâmicos se integrarem na sociedade na França. Portanto, penso que esse não é tanto um problema aqui no Brasil. Talvez devêssemos levar isso mais a sério, mas não acho que esse seja um problema no Brasil, de jeito nenhum.

\section{f) Censura}

Os grupos focais revelaram um conflito que redundou na formulação de outro tipo de negação do racismo por censura, conforme realçado nos trechos das seguintes narrativas:

18. Acho que tanto é válido os estrangeiros virem e morarem aqui, como é válido os brasileiros irem e morarem no exterior. [...] É mais uma questão de fazer seres humanos se sentirem bem-vindos, do que imigrantes se sentirem bem-vindos.

19. Realmente não sei; o que significa quando ele diz "fazê-los se sentir bemvindos"? Isso significa convidar estrangeiros aqui e dar-lhes moradia, etc...? Se é isso que ele quer dizer, não aceito.

Como ilustram as falas 18 e 19 , a opinião do participante da fala 18 foi bloqueada e censurada. A narrativa 19, indiretamente, acusou o outro entrevistado de ter uma visão excessivamente receptiva e acabou provocando a explicitação do próprio racismo.

\section{Bolivianos falam sobre suas experiências de morar em São Paulo}

Ao contrário dos brasileiros, os imigrantes bolivianos mostraram um forte favoritismo fora do grupo, elogiando os brasileiros e, frequentemente, atacando seus compatriotas bolivianos. Conflitos internos e discriminação foram, portanto, muito significativos em suas narrativas. $O$ efeito da terceira pessoa foi encontrado algumas vezes no material recolhido. Ao utilizar-se desse efeito, o entrevistado atribui experiências negativas próprias a pessoas ligadas a ele. 
Baixa autoestima - e sua consequente negação -, bem como intensa frustração causada pelo estereótipo por parte de brasileiros, foram elementos identificados como estratégias usadas para lidar com esse tumulto interno. $O$ autorretrato positivo - para esconder problemas e negar conflitos - foi também claramente reconhecido nos discursos dos imigrantes bolivianos.

Todas essas características comportamentais atuais sugerem a existência de uma ambivalência de atitude presente na comunidade boliviana, bem como uma tendência à teoria de justificação de sistema na comunidade, tanto em nível individual como grupal.

Os aspectos, a seguir elencados, permitem identificar as formas retóricas de negação do racismo, no grupo imigrante boliviano.

\section{a) Discriminação Interna}

A discriminação interna ao grupo imigrante é a primeira forma, e mais visível, de favoritismo fora do grupo. A presença e referências a conflitos internos na comunidade boliviana em São Paulo manifestaram-se através de várias situações.

O trecho 1, extraído de uma das entrevistas, mostra a tendência, que aparece constantemente nas entrevistas com os bolivianos, qual seja: a de valorizar positivamente o grupo que não é um intragrupo, mas um grupo externo - nesse caso os brasileiros -, ao mesmo tempo em que faz comentários negativos sobre o intragrupo - os bolivianos.

1. Entrevistado: Quando eu cheguei aqui, pensei que tudo fosse muito bom.

Moderador: Então, você gosta daqui?

Entrevistado: Sim, gosto. Tem sido muito bom estar aqui. [...] Os brasileiros nos ajudaram muito. [...]

Moderador: Está bem, então você está satisfeita aqui. O que você recomendaria a qualquer outra mulher boliviana que quisesse vir para São Paulo?

Entrevistado: Que... que aqui é muito bom, e que os brasileiros são muito prestativos. Aqui há de tudo.

Moderador: Então, tudo é bom...? [...]

Entrevistado: Bem, conheço pessoas que tiveram experiência ruim também, muito ruim... e eu mesma fui maltratada uma vez. [...] Os bolivianos, às vezes, nos tratam mal. Tive alguns problemas na casa onde morava, por causa de meus filhos. Eles não gostavam de nós, principalmente porque as crianças eram barulhentas.

De uma perspectiva psicológica, este relato seria um caso de auto-ódio, no qual as minorias, imigrantes e grupos sociais excluídos, podem sofrer de complexo de inferioridade, tanto individual como coletivo. De fato, estudos sociopsicológicos, após a Segunda Guerra Mundial, mostraram que grupos que sofrem de preconceito podem internalizar preconceitos da sociedade contra si mesmos e adotar certas preferências a grupos mais avantajados (ALLPORT, 1954). 
Estudos recentes, considerando a teoria de justificação de sistemas (JOST \& BURGESS, 2000), apontaram que, para tolerar todos os tipos de injustiças e desigualdades, as pessoas em situações difíceis podem suportar ou racionalizar o status quo, e reforçar, em um nível subjetivo, a ideologia e ações dominantes do grupo principal de poder. Assim, quanto mais poderoso o grupo social ao qual se pertença, maior será o favoritismo intragrupo, ao passo que aqueles que pertencem aos grupos de menor poder demonstram mais tendências ao favoritismo fora do grupo. Essas atitudes podem ser reforçadas no contexto imigratório, levando a um conflito interno dentro do grupo.

A identificação interna e positiva ao grupo imigrante somente ocorre quando se delineiam perfis sociais, econômicos ou culturais de maior status, delimitando quem pertence àquele intragrupo (JOST \& BURGESS, 2000). Desse modo, podese reconhecer - entre os imigrantes bolivianos - o favoritismo intragrupo de profissionais liberais bolivianos, que excluem os próprios bolivianos pertencentes a outros subgrupos.

Exemplo desse conflito refere-se à discriminação contra os imigrantes bolivianos recém-chegados, com baixa qualificação profissional, conforme demonstrado nas narrativas abaixo:

2. Entrevistado: Naquela época, os imigrantes bolivianos que vinham a São Paulo eram profissionais... profissionais como meu pai. Para obter documentos, era necessário passar por muitos exames, tanto psicológicos, como exame de sangue. Não como atualmente! Hoje, as pessoas da Bolívia vêm de zonas rurais, não querem estudar... mas antes não era assim. [...] Esses bolivianos que estão imigrando agora vêm de zonas rurais, mas a Bolívia não é apenas assim.

Moderador: Como é o seu relacionamento com os brasileiros?

Entrevistado: Os brasileiros recebem os estrangeiros muito bem, de forma muito diferente dos outros países. Os brasileiros recebem os estrangeiros com gentileza. [...] Mas, se você disser que é boliviano, eles têm a ideia de que os bolivianos são todos iguais. Mas nós não somos. Por exemplo, os brasileiros pensam que a Bolívia é inteiramente como a Rua Coimbra, a feira boliviana aqui. Mas, não é. Há bolivianos que vão lá, mas a Bolívia não se resume somente à feira.

Esta entrevista reforça a forma negativa de falar sobre o próprio intragrupo e até cria conflito dentro do grupo. É um tipo de separação que ocorre quando imigrantes bolivianos são definidos como não tendo educação, sendo até indesejáveis pela comunidade imigrante anterior. A narrativa revela sérias frustrações sobre a imagem da comunidade boliviana em São Paulo, a qual pode estar sendo arranhada pelos imigrantes recém-chegados, descritos como imigrantes de baixa qualificação. Por outro lado, os brasileiros são elogiados e vistos de forma absolutamente positiva. A sociedade hospedeira brasileira não recebe críticas, mesmo por estereótipos injustos. As críticas e reclamações são diretamente feitas aos membros do intragrupo, os bolivianos. 


\section{b) Baixa autoestima}

Estreitamente relacionada com esse exemplo anterior, a baixa autoestima pode ser esperada quando um grupo mostra sinais de favoritismo fora do grupo. De acordo com Jost \& Burgess (2000), grupos com favoritismo fora do grupo possuem uma tendência psicológica geral de justificar e racionalizar a ordem social existente e pensar que as relações de grupo existentes sejam legítimas e justas. Desta forma, se as relações intragrupais forem conflituosas, a tendência será de acreditar que há razões legítimas para isso e que o grupo fez algo errado para levar as relações nessa direção. Podemos ver isso realçado no extrato da seguinte entrevista:

3. Entrevistado: Às vezes, quando digo que sou boliviana, dizem que os bolivianos são ruins, que não valem nada. Eles dizem que você é boliviana, mas você sabe que os bolivianos são pessoas ruins. Aí eu digo: não, nem todos! Mas, sim, eles exploram uns aos outros. Não pagam seus funcionários, todos nós conhecemos esses casos. Os brasileiros também dizem que os bolivianos bebem muito.

Moderador: Então, os brasileiros dizem que os bolivianos bebem muito; é isso? Entrevistado: Sim, realmente, os bolivianos de fato bebem muito; é verdade! (rindo). Moderador: Isso a incomoda?

Entrevistado: Um pouco. Porque quando eu digo que sou boliviana, sempre acrescento que nem todos os bolivianos são iguais. Concordo que eles exploram uns aos outros, mas nem todos fazem isso, e quando explico isso aos brasileiros, eles entendem.

No trecho 3, a mulher boliviana reforça os estereótipos de que os bolivianos exploram uns aos outros, e que bebem demais. A legitimação desses dois estereótipos negativos reforça a ideia de que, realmente, os brasileiros estão corretos em pensar assim. A entrevistada deve, então, justificar o motivo pelo qual esses hábitos negativos existem; mas a baixa autoestima bloqueia a entrevistada e ela não resiste aos estereótipos enraizados. No fim, ela também acrescenta que os brasileiros entendem suas explicações, retratando os brasileiros como muito tolerantes e compreensivos. Esse processo, inteiramente psicológico, inverte a situação. Ao invés de rejeitar as acusações infundadas e estereotipadas, ela as legitima por meio de sua falta de resistência e de sua baixa autoestima.

\section{c) Autorretrato positivo}

Uma forma explicitada de negação, que foi possível constatar entre os participantes bolivianos, foi a negação de problemas, que resulta num autorretrato exclusivamente positivo, como ilustra o trecho 4 .

4. Entrevistado: Nunca me apresento como alguém que tenha problemas. Sempre digo, no Brasil, que vim aqui estudar.

Alguns entrevistados acreditam que falar a verdade sobre suas dificuldades 
na vida traria obstáculos a um bom relacionamento. Por isso, eles mantêm a crença de que se alguém se apresenta como uma pessoa que quer estudar, isso resulta numa imagem positiva, contrariamente ao que acontece com os migrantes econômicos, os quais são vistos de forma negativa. Migrantes econômicos são associados à pobreza e problemas.

O entrevistado, abaixo, também mostrou que está muito frustrado com a imagem negativa da Bolívia e, portanto, esforçou-se em retratar aquele país de forma branda (trecho 5):

5. Entrevistado: Criei esse projeto Bolívia Cultural, onde (sic) mostro que a Bolívia não é apenas o que muitas pessoas veem... [...] Há muitos brasileiros que entram no site e enviam e-mails dizendo que não sabiam que a Bolívia era tão bonita, etc... [...].

A intenção de retratar o próprio país positivamente é um desejo natural, porém, escondendo e negando problemas continuamente. Isso ocorre pelo medo de rejeição, que é uma realidade comum entre os imigrantes bolivianos em São Paulo.

\section{d) Efeito terceira pessoa}

O efeito terceira pessoa é um padrão semântico por meio do qual as pessoas conseguem encontrar uma desculpa para se livrar de uma situação, de um caso, de um exemplo mencionado. Isso significa que a pessoa é capaz de se referir a uma humilhação, a um embaraço potencial, ou a um caso proibido ideológica e moralmente, colocando a culpa em outras pessoas que não estejam presentes na ocasião da narração da história. De acordo com Billig (2006), quando as pessoas usam estruturas de efeito terceira pessoa, estão, na realidade, reivindicando indiretamente que os outros têm essa opinião, ou que tal fato aconteceu com uma terceira pessoa, mas com elas não; portanto, elas podem resistir, não compartilham aqueles pontos de vista, não terão essas experiências negativas (trecho 6).

6. Entrevistado: Há pessoas que realmente tiveram experiências ruins [...].

$O$ efeito terceira pessoa produz otimismo irrealista e impactos impessoais, sendo esse alívio psicológico a essência dessas formas retóricas. Assim, como todas as formas de negação, isso faz as pessoas recusarem a realidade.

\section{Tipos de Negação}

Uma negação é um dispositivo semântico que contém uma parte aparentemente neutra do "nós", e uma parte claramente negativa "deles" ou dos "outros". Essa estrutura semântica é tão característica que adquire múltiplas facetas. De acordo com Petrova, "Uma negação pessoal é tão típica da maioria dos discursos contemporâneos que pode ser vista como um marcador ideológico" (2000, p. 32). 
Abaixo, apresentamos algumas formas de negação que compuseram as narrativas dos brasileiros acerca dos imigrantes bolivianos na cidade de São Paulo.

a) negação do racismo baseada em ignorância aparente

Não conheço muito desse tópico, mas ouvi dizer que, embora eles aleguem ter conflitos aqui, não retornam à Bolívia. Isso significa que devem ter condições ainda piores lá.

\section{b) negação do racismo baseada na transferência}

Outros mecanismos servem para neutralizar a primeira parte da frase; isto é, transferência, empatia aparente, ou até mesmo negação explícita podem formar a base das negações.

Não participei, mas ouvi muitos comentários no ônibus, tais como "Olhe! Há tantos bolivianos aqui"... e assim por diante.

c) negação do racismo baseada na empatia aparente

Tenho certeza de que eles têm muitas dificuldades, mas o Brasil também tem muitos problemas, de modo que não podemos ajudá-los mais do que já o fazemos...

\section{d) negação do racismo baseada na negação explícita}

Por exemplo, o bolsa família... digo... não estou reclamando aqui, mas muitas pessoas estão... estão reclamando que os que recebem bolsa família são preguiçosos e criminosos, etc...

\section{Considerações Finais}

O estudo permite avançar em aspectos importantes na configuração das relações sociais entre brasileiros e bolivianos, na cidade de São Paulo. A pesquisa confirma que a repressão e a negação discursiva se tornaram a principal técnica na luta contra a realidade, como forma de autoproteção (FREUD, 1950): ao lidar com a realidade, as pessoas se recusam a vê-la e expressam suas experiências através da negação.

De modo geral, predominou o favoritismo intragrupo, entre brasileiros, e o favoritismo fora do grupo, entre imigrantes bolivianos; tais favoritismos foram marcados por papéis de posição de poder e status socioeconômico.

A retórica social dominante do grupo de brasileiros enfatizou o país como nação receptiva à imigração estrangeira. Argumentam que os imigrantes ("o outro") devem valorizar o fato de estar aqui, já que "nós" brasileiros somos discriminados no exterior. Outra retórica que reforça a posição de poder da sociedade hospedeira sobre os imigrantes bolivianos baseia-se nos discursos que buscaram reduzir a ênfase no estrangeirismo como base de discriminação.

No caso das entrevistas com o grupo de imigrantes bolivianos, predominou o tipo de retórica de elogio, tal como "os brasileiros são bons para nós, ajudam-nos muito", com o favoritismo fora do grupo. O favoritismo fora do grupo em direção à minoria sem poder e o favoritismo intragrupo em direção ao lado poderoso da sociedade hospedeira resultam na manutenção do status quo. Para tolerar 
todos os tipos de desigualdades, a comunidade de imigrantes bolivianos, bem como a sociedade hospedeira brasileira, dão suporte ou racionalizam o status quo, mesmo quando isso contradiz seu próprio autointeresse.

\section{Nota}

1 - O estudo faz parte do Projeto Temático "Observatório das Migrações em São Paulo: fases e faces do fenômeno migratório no Estado de São Paulo" (FAPESP/CNPq/ NEPO-UNICAMP).

\section{Referências}

ALLPORT, G. The Nature of Prejudice. Reading, MA: Addison-Wesley, 1954.

ARENDT, H. 'On Humanity in Dark Times: Thoughts about Lessing'. In: ARENDT, H. (org.). Men in Dark Times. London: Jonathan Cape, 1970.

BAENINGER, R. Observatório das Migrações em São Paulo: fases e faces do fenômeno migratório no Estado de São Paulo. Projeto Temático FAPESP. Campinas: Núcleo de Estudos de População - Unicamp, 2009.

BILLIG, M. Discoursive, rhetoric and ideological messages. In: MCGARTZ, C. \& HASLAM (orgs.). The message of Social Psychology: perspectives in mind and society. Oxford: Blackwell, 1997.

BURMAN, E. \& PARKER, I. (orgs.). Discourse analytic research. Repertoires and Readings of Text in Action. London: Routledge, 1993.

EDWARDS, D. \& POTTER, J. Discursive Psychology. London: Sage, 1992.

EDWARDS, D. \& POTTER, J.. Language and causation: A discursive action model of description and attribution. Psychological Review. no 100, 1993, p. 23-41.

FREUD, S. Totem and Taboo. New York: W.W. Norton \& Co, 1950.

JOST, J. T. \& BURGESS, D. Attitudinal ambivalence and the conflict between group and system justification motives in low status groups. Personality and Social Psychology Bulletin. $\mathrm{n}$ 은 26, 2000, p. 293-305.

PETROVA, D. 'The Denial of Racism', Roma Rights - Newsletter of the European Roma Rights Centre. N. 4, 2000, p. 26-38.

PERES, R. Mulheres na Fronteira: a migração de bolivianos para Corumbá - MS (Tese de Doutorado em Demografia) - Universidade Estadual de Campinas, 2009.

POTTER, J. \& WETHERELL, M. Discourse and Social Psychology. London: Sage, 1987.

POTTER, J. \& WETHERELL, M. Discourse Analysis. In: SMITH, J. A.; HARRE, R. \& VAN LANGENHOVE, L. (orgs.) Rethinking methods in Psychology. London: Sage, 1995.

SILVA, S. A. Costurando sonhos - trajetória de um grupo de imigrantes bolivianos em São Paulo. São Paulo: Paulinas, 1997.

SILVA, S. A. Bolivianos em São Paulo: entre o sonho e a realidade. Estudos Avançados, v. 20, no 57, 2006, p.157-170.

SIMAI, S. \& BAENINGER, R. The Denial of Racism: The Case of Bolivian Immigrants in Sao Paulo. In: SIMAI, S.; BAENINGER, R. \& HOOK, D. (orgs.) Exploring Contemporary Racism: Denial and Affective Logic. VDM Verlag Publishing: Germany, 2011.

VAN DIJK, T. A. Prejudice in Discourse: An Analysis of Ethnic Prejudice in Cognition and Conversation. Amsterdam: J. Benjamins Co., 1984.

VAN DIJK, T. A. Communicating Racism: Ethnic Prejudice in Thought and Talk. Newbury Park, CA: Sage Publications, 1987.

VAN DIJK, T. A. Denying racism: Elite discourse and racism. In: SOLOMOS, J. \& WRENCH, J. (ogs.). Racism and Migration in Western Europe. Oxford: Berg, 1993, p. 179-193. 
VAN DIJK, T. A. Discourse and racism. In: GOLDBERG, D. \& SOLOMOS, J. (orgs.), The Blackwell Companion to Racial and Ethnic Studies. Oxford: Blackwell, 2004, p. 145-159.

WETHERELL, M. \& POTTER, J. Mapping the Language of Racism: Discourse and the Legitimation of Exploitation. New York: Columbia University Press, 1992.

WODAK, R. et al. "Wir sind alleunschuldige Triter". Diskurshistorische Studien zum Nachkriegsantisemitismus ["We are all innocent perpetrators." Discourse Historic Studies in Postwar Antisemitism]. Frankfurt/Main: Suhrkamp, 1990.

\title{
RESUMO
}

O artigo objetiva analisar na prática discursiva, como prática social, vários exemplos discursivos da negação da existência de racismo, xenofobia e conflitos em relação à presença boliviana na cidade de São Paulo. $O$ estudo indica o proeminente papel que a negação desempenha no discurso contemporâneo e, consequentemente, seus reflexos nas relações raciais e étnicas entre os imigrantes bolivianos e os brasileiros na cidade de São Paulo.

Palavras-chave: análise do discurso; racismo; bolivianos.

\begin{abstract}
This article attempts to analyze contemporary forms of racism, xenophobia and inter-ethnic conflicts through the study of denial of racism as a discursive form and social practice in the case of Bolivian immigrants in the city of Sao Paulo. The study examines the prominent role of denial of racism in contemporary discourse as well as its impact on racial and ethnic relations between Bolivian immigrants and Brazilians in the city of Sao Paulo.
\end{abstract}

Keywords: discourse analysis; racism; bolivians. 